\title{
Utilizing the lateral excess for autologous augmentation in massive weight loss patients
}

\author{
Martin Söderman ${ }^{1}$, Peder Ikander ${ }^{1}$, Slaven Boljanovic ${ }^{2}$, Gudjon Leifur Gunnarsson $^{3}$, Jens Ahm Sørensen ${ }^{1}$, \\ Jørn Bo Thomsen ${ }^{1}$ \\ ${ }^{1}$ Department of Plastic Surgery, Odense University Hospital, Odense, Denmark; ${ }^{2}$ Clinic for Plastic Surgery, Mølhom Private Hospital, Vejle, \\ Denmark; ${ }^{3}$ Department of Plastic Surgery, Telemark Hospital, Skien, Norway \\ Correspondence to: Jørn Bo Thomsen. Department of Plastic Surgery, Odense University Hospital, Odense, Denmark. Email: Joern.Bo.Thomsen@rsyd.dk.
}

\begin{abstract}
The number of patients in need of a mastopexy with autologous augmentation after massive weight loss (MWL) increases along with the increasing number of bariatric surgeries. The primary aim of this paper was to visualize how we utilize the lateral excess of the breast for auto augmentation. The secondary aim was to assess the outcome using the LOPOSAM technique in a larger study population. This retrospective study included $72 \mathrm{MWL}$ patients aged $40 \pm 9$ years undergoing a bilateral LOPOSAM procedure, between March 2015 and April 2018. All patients had undergone a weight loss of more than 15 BMI units, had a BMI of less than $30 \mathrm{~kg} / \mathrm{m}^{2}$ at the time of surgery and functional problems due to excess or lax skin. Patient demographics, comorbidities, cause of MWL, operative time and complications were recorded. The mean weight loss was $58 \pm 18 \mathrm{~kg}$ or $21 \pm 6 \mathrm{BMI}$ units. The mean operative time was $97 \pm 39$ minutes. The surgical goal was achieved in all patients. Three patients (4\%) experienced hematomas requiring surgical intervention. The utilization of the lateral excess of the breast for auto augmentation in MWL patients is visualized. The long term results using the LOPOSAM mastopexy technique shows that the technique is quick, safe and with a low rate of complications.
\end{abstract}

Keywords: Breast; auto augmentation; massive weight loss (MWL)

Submitted Feb 14, 2019. Accepted for publication Apr 01, 2019.

doi: $10.21037 /$ gs.2019.04.01

View this article at: http://dx.doi.org/10.21037/gs.2019.04.01

The number of patients needing a mastopexy with autologous augmentation after massive weight loss (MWL) has increased proportionally with the increasing number of bariatric surgeries (1). The breasts in MWL patients often appear wide and ptotic, due to recession and lateralization of the inframammary crease and breast base, which is caused by loosening of supportive fibrous tissue and stretching of Cooper's ligaments (Figure 1) (2-4). Several techniques in MWL patients describe reshaping the breasts through glandular re-modeling, parenchymal plication, dermal suspension and/or auto augmentation (3-6).

We have recently published our preliminary results using the LOPOSAM technique, where we combine a superomedial nipple/areolar pedicle and a subglandular placed inferior and central mound flap for auto augmentation to reshape the breast in MWL patients (7).

The primary aim of this paper was to visualize how we utilize the lateral excess of the breast, as a part of the auto augmentation in an extended version of the LOPOSAM technique (Figure 2). The secondary aim was to assess the long term outcome using the LOPOSAM technique in a larger study population.

\section{Methods}

This retrospective study included 72 MWL patients, aged $40 \pm 9$ years, having a bilateral mastopexy with auto augmentation, between March 2015 and April 2018 at Mølholm Private Hospital, Vejle, Denmark and at the Department of Plastic Surgery at Odense University 


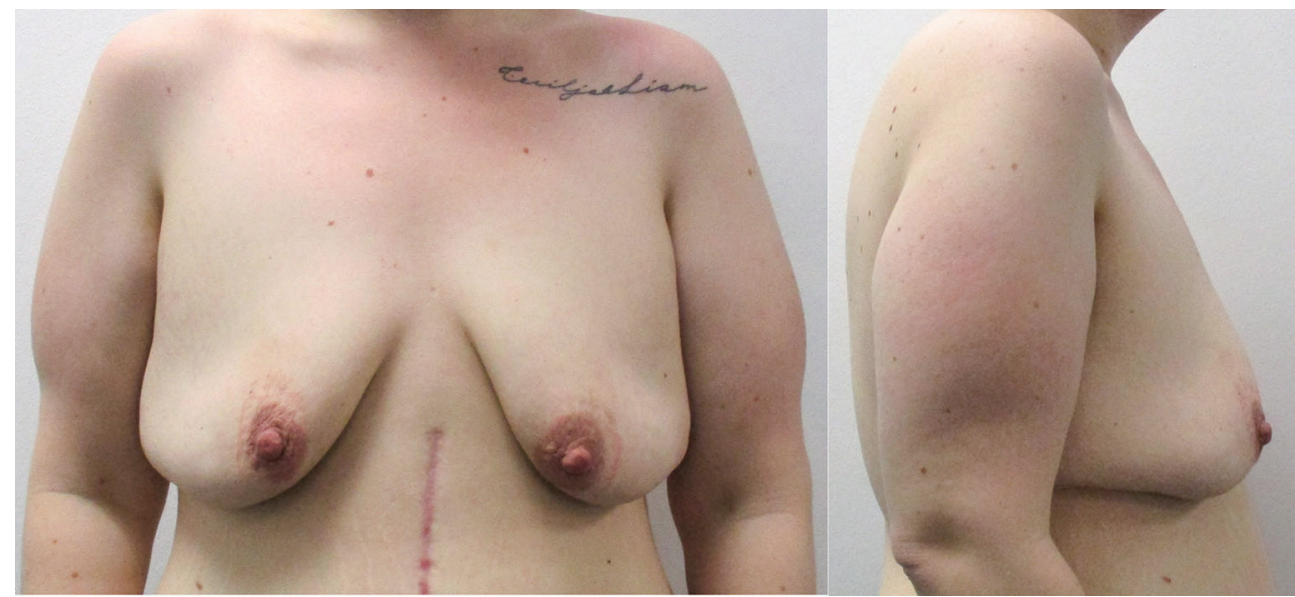

Figure 1 Patient before surgery.

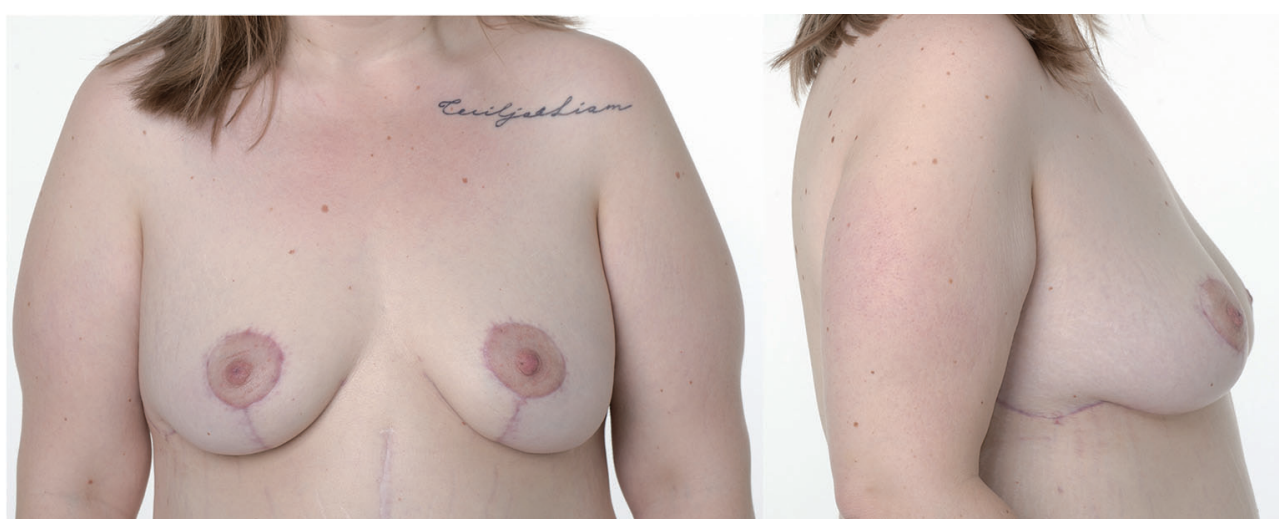

Figure 2 Patient after surgery.

Hospital, Odense, Denmark.

All patients were referred from a public hospital due to excess skin following MWL; a weight loss of more than $15 \mathrm{BMI}$ units, a BMI of less than $30 \mathrm{~kg} / \mathrm{m}^{2}$ at the time of surgery and functional problems due to excess or lax skin. We recorded patient demographics, comorbidities, cause of MWL, operative time and complications.

This study has been approved by the Danish Data Protection Agency (Journal nr. 17/3091), and the Danish Patient Safety Authority (3-3013-227/1).

\section{Operative technique: lateral excess (Figure 3)}

The video shows a MWL patient having a mastopexy, where the lateral excess is utilized for auto augmentation based on an inferior and central mound pedicle (Figure 3). The location of the keyhole was projected to the skin, at the level of the inframammary crease. The vertical lines were drawn caudally from the keyhole at a narrow angle. A standard length of approximately $5.5 \mathrm{~cm}$ was applied. The rest of the drawing was completed using a standard wise pattern. The upper border of the breast and the location of the subglandular pocket were drawn. The lateral excess was marked. Surgery commenced by marking the lines using a scalpel. The entire area within the wise pattern was deepithelialized, except the nipple areola complex (NAC). In this case we used a superior pedicle for the NAC. The inferior and central pedicled lateral excess was carefully dissected and mobilized, in order not to damage the anterior and lateral intercostal artery perforators integrated in the flap. The surgeon carefully identifies the perforators during dissection of the flap. The dissection medially is continued until the flap can reach the top of the subglandular pocket. Sometimes lateral perforators have to be cut to enable the 


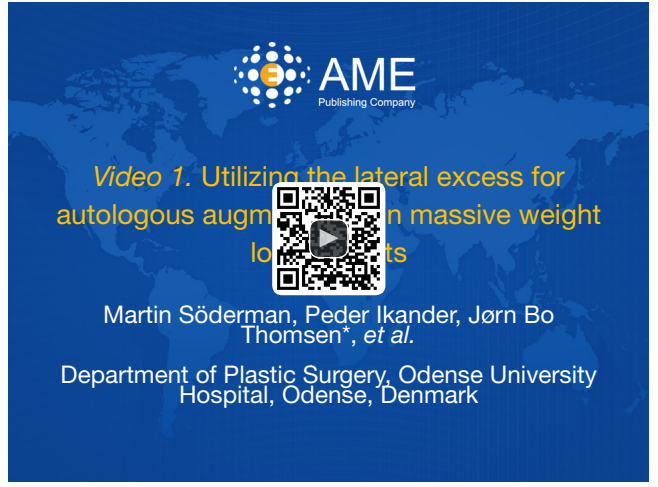

Figure 3 Utilizing the lateral excess for autologous augmentation in massive weight loss patients (8).

Available online: http://www.asvide.com/watch/32979

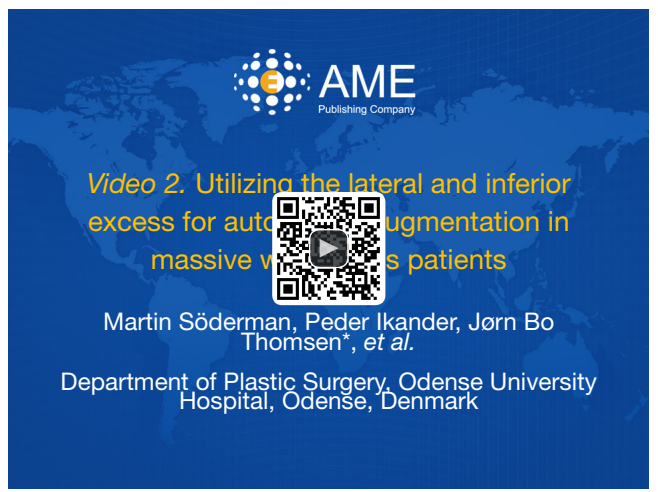

Figure 4 Utilizing the lateral and inferior excess for autologous augmentation in massive weight loss patients (9).

Available online: http://www.asvide.com/watch/32980

flap to reach the top of the pocket. However, it seems that the inferior and central mound vascular supply is adequate. Preoperative imaging of the abundant perforators is not needed as they are always to found within the flap base (7). The superomedial subglandular pocket was dissected using monopolar cautery. The lateral excess was rotated into the subglandular pocket and sutured with a PDS 2.0 suture at the top of the pocket. The skin was sutured over the re-shaped parenchyma in two layers using Vicryl 3.0 and Monocryl 3.0. The circumference of the areola was sutured using a nylon 4.0 suture.

\section{Operative technique: lateral excess folded onto the inferior and central excess (Figure 4)}

This video shows a MWL patient having a mastopexy where the patient's inferior and lateral excess was combined, and utilized for auto augmentation based on an inferior and central mound pedicle (Figure 4). The markup was similar to the one described above. The inferior and lateral excess, as well as the area within the wise pattern was deepithelialized. The superomedial subglandular pocket was dissected using monopolar cautery. The lateral excess was dissected, mobilized and folded onto the central and inferior excess. The tip of the combined auto augmentation was sutured to the top of the subglandular pocket using a PDS 2.0 suture. An extra PDS 2.0 was used to medialize the auto augmentation. We used a superomedial pedicle for the NAC, which was rotated into the keyhole and sutured in two layers using Vicryl 3.0 and nylon 4.0. The skin was sutured by Vicryl 3.0 and Monocryl 3.0.

\section{Results}

We performed 72 bilateral LOPOSAM procedures between March 2015 and April 2018, 24 at Mølholm Private Hospital and 48 at the Department of Plastic Surgery at Odense University Hospital. The mean age was $40 \pm 9$ years. The majority, 55 (76\%), of the patients had lost weight after having a gastric bypass operation, whereas one $(1 \%)$ had a gastric banding procedure and $16(22 \%)$ had lost weight due to dietary changes and exercise. Prior to the MWL the patients had a mean weight of $129.8 \pm 23.8 \mathrm{~kg}$ and a BMI of $46 \pm 7.4$. Prior to the LOPOSAM procedure they had a mean weight of $72 \pm 10.2$ and a BMI of $25.5 \pm 2.8$, giving a mean weight loss of $57.8 \pm 18.4 \mathrm{~kg}$ or $20.5 \pm 6.3 \mathrm{BMI}$ units. Two (3\%) patients had diabetes and eight (11\%) had hypertension, while 17 (24\%) had one or more other comorbidities, for details regarding patient characteristics Table 1 .

The mean operative time was $97 \pm 39$ minutes. The surgical procedure was completed as planned in all patients. All patients expressed that they were content with the result at three month follow-up. All but one (1\%) patient received drains. Sixty-eight (94\%) patients were discharged the day after surgery, the remaining four stayed for another 1-2 days, due to excessive drainage.

Sixteen patients $(22 \%)$ experienced at least one complication, three of which were major and required surgical intervention (hematomas).

\section{Comments}

We have presented and visualized the principles and technique, by which the extended LOPOSAM 
Table 1 Patient characteristics $(n=72)$

\begin{tabular}{|c|c|}
\hline Characteristics & Outcomes \\
\hline Age (years) & $40 \pm 9$ \\
\hline Height (cm) & $168 \pm 7.0$ \\
\hline Tobacco & $5 / 72$ \\
\hline Diabetes & $2 / 72$ \\
\hline Hypertension & $8 / 72$ \\
\hline Gastric bypass & $55 / 72$ \\
\hline Gastric banding & $1 / 72$ \\
\hline Diet and exercise & $16 / 72$ \\
\hline Weight prior to $\mathrm{MWL}^{\dagger}(\mathrm{kg})$ & $129.8 \pm 23.8$ \\
\hline Weight after $\mathrm{MWL}^{\dagger}(\mathrm{kg})$ & $72 \pm 10.2$ \\
\hline$\Delta$ Weight $^{\dagger}(\mathrm{kg})$ & $57.8 \pm 18.4$ \\
\hline 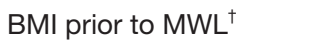 & $46 \pm 7.4$ \\
\hline $\mathrm{BMI}$ after $\mathrm{MWL}^{\dagger}$ & $25.5 \pm 2.8$ \\
\hline$\Delta \mathrm{BMI}^{\dagger}$ & $20.5 \pm 6.3$ \\
\hline Operative time (minutes) & $97 \pm 39$ \\
\hline
\end{tabular}

Means with standard deviations. ${ }^{\dagger}, \mathrm{n}=71$. MWL, massive weight loss.

procedure can be used to utilize the lateral excess for auto augmentation. Furthermore, we have presented our results with the LOPOSAM technique in a larger study population. MWL patients often experience that the breasts migrate inferior and lateral as a consequence of the massive weight gain followed by the MWL $(3,4)$. This lateral excess can be utilized as a part of an auto augmentation when performing a mastopexy. This is especially important in patients, where most of the excess is localized laterally and in patients with small breasts, where all of the breast tissue should be reallocated in a medial and cranial direction onto the original breast base. The utilization of the lateral excess as a part of an extended LOPOSAM mastopexy enables the surgeon to tailor the auto augmentation for the individual patient according to the location of the available tissue.

We have performed a total of 144 mastopexies with auto augmentation in 72 patients, all of which reported satisfaction with the result at the three month follow-up. This confirms our initial experience with the technique as being quick, with a high rate of satisfaction and limited number of complications (7). The mean operating time using the LOPOSAM and extended LOPOSAM technique is quite fast compared to other mastopexies with auto augmentation (10). However, compared to Rubin's mastopexy there is a drawback of using a superior or superomedial pedicle, which is the lack of or reduced sensation in the NAC $(11,12)$. We aim to test if the use of a lateral pedicle may enable us to better preserve the NAC sensation. The LOPOSAM technique and extended LOPOSAM technique is a versatile technique for reshaping the breast in MWL patients using the excess tissue within the breast for auto augmentation.

\section{Acknowledgments}

None.

\section{Footnote}

Conflicts of Interest: The authors have no conflicts of interest to declare.

Informed Consent: Written informed consent was obtained from the patient for publication of this manuscript and any accompanying images.

\section{References}

1. English WJ, DeMaria EJ, Brethauer SA, et al. American Society for Metabolic and Bariatric Surgery estimation of metabolic and bariatric procedures performed in the United States in 2016. Surg Obes Relat Dis 2018;14:259-63.

2. Gunnarson GL, Froyen JK, Sandbu R, et al. Plastic surgery after bariatric surgery. Tidsskr Nor Laegeforen 2015;135:1044-9.

3. Colwell AS, Driscoll D, Breuing KH. Mastopexy techniques after massive weight loss: an algorithmic approach and review of the literature. Ann Plast Surg 2009;63:28-33.

4. Losken A. Breast reshaping following massive weight loss: principles and techniques. Plast Reconstr Surg 2010;126:1075-85.

5. Hamdi M, Van Landuyt K, Blondeel P, et al. Autologous breast augmentation with the lateral intercostal artery perforator flap in massive weight loss patients. J Plast Reconstr Aesthet Surg 2009;62:65-70.

6. Rubin JP. Mastopexy after massive weight loss: dermal suspension and total parenchymal reshaping. Aesthet Surg J 2006;26:214-22.

7. Ikander P, Gad D, Gunnarsson GL, et al. Simple 
Reshaping of the Breast in Massive Weight Loss

Patients: Promising Preliminary Results. Ann Plast Surg 2017;78:145-8.

8. Söderman M, Ikander P, Boljanovic S, et al. Utilizing the lateral excess for autologous augmentation in massive weight loss patients. Asvide 2019;6:294. Available online: http://www.asvide.com/watch/32979

9. Söderman M, Ikander P, Boljanovic S, et al. Utilizing the lateral and inferior excess for autologous augmentation in massive weight loss patients. Asvide 2019;6:295. Available online: http://www.asvide.com/watch/32980

10. Rubin JP, Gusenoff JA, Coon D. Dermal suspension and

Cite this article as: Söderman M, Ikander P, Boljanovic S, Gunnarsson GL, Sørensen JA, Thomsen JB. Utilizing the lateral excess for autologous augmentation in massive weight loss patients. Gland Surg 2019;8(Suppl 4):S271-S275. doi: 10.21037 /gs.2019.04.01 parenchymal reshaping mastopexy after massive weight loss: statistical analysis with concomitant procedures from a prospective registry. Plast Reconstr Surg 2009;123:782-9.

11. Hamdi M, Van Landuyt K, Tonnard P, et al. Septum-based mammaplasty: a surgical technique based on Wuringer's septum for breast reduction. Plast Reconstr Surg 2009;123:443-54.

12. Skoog T. A technique of breast reduction; transposition of the nipple on a cutaneous vascular pedicle. Acta Chir Scand 1963;126:453-65. 